\title{
Utilizando Tecnologia Computacional na Análise Quantitativa de Movimentos: Uma Atividade para Alunos do Ensino Médio
}

\author{
Computer Technology in Quantitative Analysis of Movements: An Activity for High School Students
}

\author{
Mônica G. Menezes de Magalhães, Dietrich Schiel, Iria Müller Guerrini, Euclydes Marega Jr. \\ monica@rc.unesp.br; dietrich@cdcc.sc.usp.br;iria@cdcc.sc.usp.br; euclydes@if.sc.usp.br \\ Centro de Divulgação Científica e Cultural da USP, São Carlos-SP, (CDCC) \\ Instituto de Física de São Carlos/USP, (IFSC)
}

Recebido em 4 de março, 2002. Aceito em 2 de maio, 2002.

\begin{abstract}
Neste artigo é descrito o projeto "Análise Quantitativa de Movimentos", que está sendo desenvolvido por alunos e professores de quatro escolas públicas da região de São Carlos-SP, sob a orientação da equipe do CDCC/USP. A análise de movimentos reais e dos obtidos no laboratório é realizada utilizando-se um software desenvolvido pelo CDCC e na linguagem LOGO. Dados da avaliação do projeto são apresentados.

This article describes the project "Quantitative Analysis of the Movements" that has been developed by students and teachers of four public schools of the area of São Carlos-SP, oriented by researchers from CDCC/USP. The analysis of the real movements and those got in the laboratory is done using a software developed by CDCC and the LOGO language. Data of the project the evaluation are presented.
\end{abstract}

\section{Introdução}

O computador na sala de aula pode ser uma ferramenta cognitiva para o aluno, ao criar um ambiente de aprendizagem tal que nele os alunos possam desenvolver habilidades em um contexto que faça parte da sua vida real [1], em que haja aprendizagem colaborativa [2], ativa, facilitada, e os alunos possam construir a sua interpretação do mundo real, interiorizando os conhecimentos e organizando-os.

Este projeto está sendo desenvolvido por alunos e professores de quatro escolas públicas da região de São Carlos - EE Cândido Portinari (Batatais-SP), EE Tomas Watelly (Ribeirão Preto-SP), EE Álvaro Guião e EE Juliano Neto (São Carlos-SP) -, sob a orientação da equipe do Centro de Divulgação Científica e Cultural (CDCC) / USP-SC, que promove as habilidades necessárias para desenvolver novas tecnologias na sala de aula [3].

A análise quantitativa de movimentos reais e dos realizados em laboratório é executada utilizando-se o software SAM (Sistema de Análise Digital de Movimentos), desenvolvido pelo bolsista do CDCC, Edson Minatel (1998/99) no projeto Educadi, financiado pelo CNPq, envolvendo os conceitos de mecânica gráfica (http://educar.sc.usp.br/fisica/fisica.html). A linguagem LOGO foi utilizada para simular os movimentos filmados.
Para que os alunos do ensino médio possam apreender os conceitos de onda, comprimento de onda, frequiência e fazer analogia com os conceitos de ótica geométrica (lentes, espelhos), foi realizado o estudo das ondas [4] em uma cuba de onda, utilizando-se o software SAM.

Novas imagens e inovações gráficas foram obtidas como parte dos resultados do projeto, formando-se um Banco de Imagens para que alunos e professores que não possuam equipamentos necessários possam usufruir dessas imagens, bem como para que outros alunos e professores possam compartilhar de suas experiências proporcionando uma atividade colaborativa.

\section{Fundamentação Teórica: O Uso do Computador no Pro- cesso Ensino/Aprendizagem}

Duas teorias se destacam como básicas para o desenvolvimento, seleção e uso do computador na educação [5]: uma com base behaviorista e outra com base construtivista.

Na visão behaviorista, o professor é visto como manipulador do ambiente de aprendizagem. As aulas são planejadas passo a passo, tal que haja estímulo - resposta e reforço para atingir um objetivo. A modificação do 
comportamento do aluno é através do condicionamento. $\mathrm{O}$ ambiente de aprendizagem é estruturado rigidamente a fim de que o aluno possa ser moldado para adquirir mudanças desejáveis (aprendizagem). O aluno é um receptor de conhecimento, e o professor o transmissor.

Em contraste com à visão behaviorista, a visão construtivista vê a educação como inseparável da vida real. O papel do professor é monitorar o crescimento cognitivo e o amadurecimento do aluno, contribuindo para a construção pessoal do aluno [6]. De acordo com Simon [7], a aprendizagem construtivista é necessariamente: ativa (desenvolvida com base na experiência), acumulativa, integrativa, reflexiva e os aprendizes determinam os objetivos da aprendizagem.

$\mathrm{O}$ aluno desenvolve a sua própria imagem e usa isto para construir novo conhecimento, fundamentado no seu conhecimento anterior e habilidades [8]. A aprendizagem, segundo Kosman [9], é um processo ativo e construtivo por meio do qual o aprendiz gerencia os recursos cognitivos disponíveis para criar um novo conhecimento extraindo informações do ambiente. É também colaborativa no sentido de promover colaboração com outros para mostrar perspectivas múltiplas de um problema particular ao chegar a posições individuais $[10]$.

O uso do computador no processo ensino/aprendizagem apresenta dois enfoques [11]: aprendendo do computador e aprendendo com o computador (ferramentas mentais ou cognitivas).

O computador é programado para o aluno adquirir conhecimentos ou habilidades préestabelecidas. Como exemplo, temos:

- Exercício e prática (drill and practice): muito usado nos anos 70 e 80 e ainda hoje, incorporava a visão behaviorista de Skinner de reforço de associações de estímulo e resposta. Os aprendizes resolviam os problemas, entravam com as respostas e já tinham uma realimentação da acuracidade da sua resposta, promovendo uma automaticidade. Ainda hoje esse tipo de programa é usado para aprender línguas, memorizar informações, cursos nas empresas, aprender computação e outros.

- Tutorial: este programa tem como finalidade responder às diferenças individuais na aprendizagem, fornecendo instrução de reforço, quando os alunos respondem incorretamente. A limitação dos tutoriais é que os alunos adquirem um conhecimento pronto.

- Sistemas Tutoriais Inteligentes (TI): desenvolvidos nos anos 80 e 90 por pesquisadores de Inteligência Artificial (IA) para ensinar a resolver problemas e adquirir conhecimento. O que é acrescentado ao Tutorial são modelos especialistas que descrevem o raciocínio ou estratégias que um especialista usaria para resolver um problema.

\section{Aprendendo com o computador}

O computador pode ser utilizado como uma ferramenta auxiliar na aprendizagem. Através de ferramentas mentais (mindtools) ou cognitivas, o aprendiz dentro de um contexto real constrói seu conhecimento de uma forma intelectual (crítico, criativo, e pensamento de alta ordem) e social (cooperação). As ferramentas cognitivas que podem ser usadas no processo de ensino/aprendizagem via computador são: planilhas, banco de dados, e-mail, Web, fórum de discussão, programação de computador, hipermídia, hipertexto, e ambientes de aprendizagem envolvendo várias ferramentas. $\mathrm{O}$ autor apresenta várias ferramentas que, em grau maior ou menor podem ser usadas.

Um ambiente de aprendizagem pode ser criado, utilizando-se os recursos já citados anteriormente e mais: software que simula o mundo real fornecendo aos alunos uma experiência direta, envolvendo-os como aprendizes ativos e podendo fazer hipóteses e observar os efeitos destas hipóteses [12]; linguagem de computador como a linguagem LOGO que é uma linguagem de programação interativa para todas as idades com recursos poderosos tais como métodos, recursão e a manipulação de programas como dados, fornecendo um ambiente de programação interativo [13] [14]; situação desafiadora em que o aluno precisa pesquisar na Web ou consultar um banco de dados para resolvê-la; e outros.

\section{Metodologia}

Os movimentos reais ou os obtidos no laboratório são filmados pelos alunos com uma câmera de vídeo para registro do movimento e, após a captura da imagem para o computador, utiliza-se o software SAM para a análise quantitativa deste movimento. Estas imagens também podem ser capturadas da televisão. Foram filmados movimentos do cotidiano e os simulados no laboratório tais como: movimento de um carro na rua, movimento de uma pessoa andando, movimento de uma bola em um jogo de futebol, vôlei, tênis, pingue-pongue, movimento de uma bola em queda livre, movimento de um projétil, movimento de um pêndulo e outros.

Utilizando-se o software SAM, o arquivo do filme com extensão avi é mostrado quadro a quadro, e os alunos podem obter os dados referentes à posição do objeto, assinalando essas posições com o "marcador" e medindo a distância com uma "régua virtual". O intervalo de tempo entre um quadro e outro é mostrado no próprio software. Sendo a captura, por exemplo, realizada a 30 quadros/s, o tempo entre um quadro e outro será $1 / 30 \mathrm{~s}$.

Ao analisarem as medidas quantitativas dos movimentos, os alunos, sob a orientação dos professores, vão descobrindo quando que um movimento é acelerado ou não, unidimensional ou bidimensional, qual o tipo de trajetória (retilínea, circular ou parabólica).

Com os valores dos parâmetros calculados (espaço, tempo, velocidade, aceleração e outros), os alunos preenchem uma tabela via Internet, programada em Perl, que corrige os valores on-line, e simultaneamente esta tabela é enviada ao professor distante (da equipe do CDCC), que discute, através de e-mail, os valores físicos encontrados.

Os alunos também aprendem a programar os movimentos em linguagem LOGO e a executar o programa sobre a imagem bmp com estrobo (figura 1) ou com as 
posições assinaladas, obtida no SAM [15].

\section{Movimento de projétil 30 quadros/s - CDCC - USP}

\section{$20 \mathrm{~cm}$}

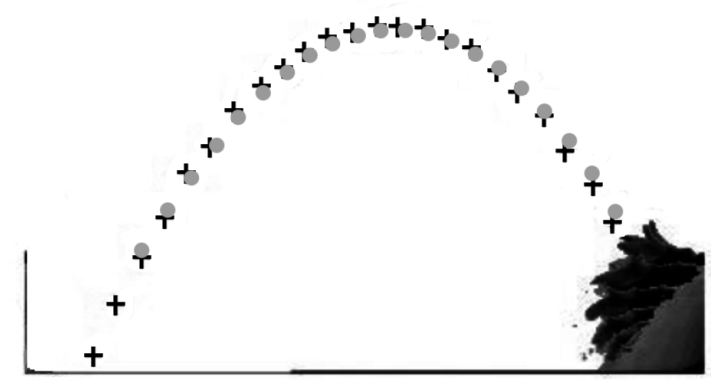

$a_{y}=980 \mathrm{~cm} / \mathrm{s}^{2} v_{x}=180 \mathrm{~cm} / \mathrm{s} \quad v_{y \text { inicial }}=330 \mathrm{~cm} / \mathrm{s}$

Figura 1. Trajetória do cursor (+) LOGO - "tartaruga" aproximadamente coincidente com a trajetória da bola.

\section{Banco de Imagens}

As filmagens de diferentes movimentos elaboradas pelos professores e alunos das escolas públicas e pela equipe do CDCC estão armazenadas em um Banco de Imagens. A finalidade deste Banco de Imagens é a de compartilhar experiências entre alunos e professores de diferentes localidades proporcionando uma atividade colaborativa, bem como facilitar o acesso a essas imagens aos alunos e professores que não possuem equipamentos necessários para a realização das filmagens. Com o Banco de Imagens é possível utilizar o software SAM compartilhando-se imagens entre alunos e entre professores.

São partes integrantes do Banco de Imagens as Figs. 2 a 6 exibidas abaixo. O Banco de Imagens está disponível na Internet, no site do SAM [15]. Neste site também são encontrados os manuais do software SAM e da câmera de vídeo, a fundamentação teórica, os programas dos movimentos em linguagem LOGO, os roteiros experimentais e as tabelas on-line.

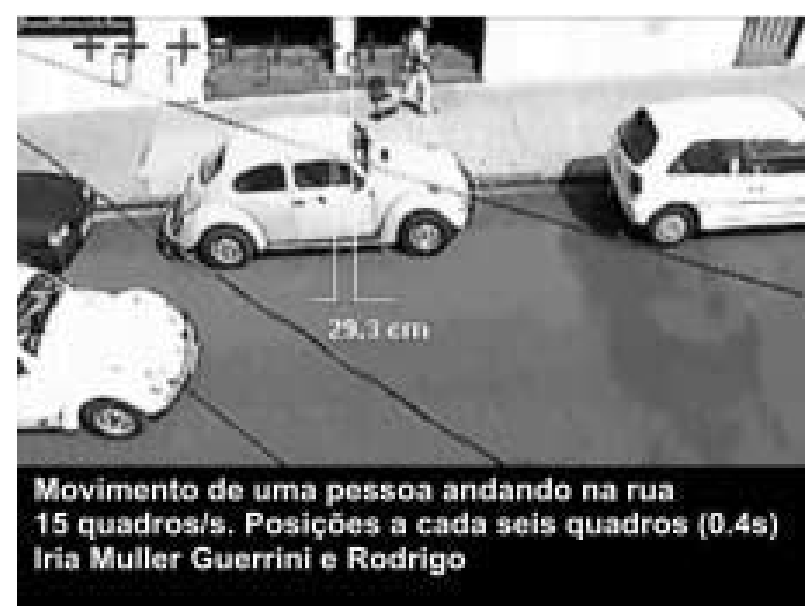

Figura 2. Movimento de uma pessoa andando na rua.

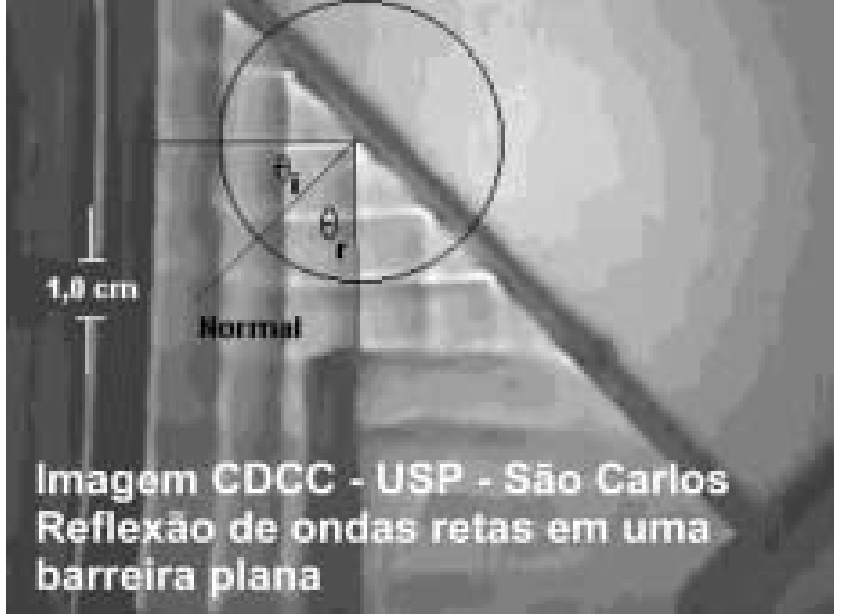

Figura 3. Medidas - cuba de ondas.

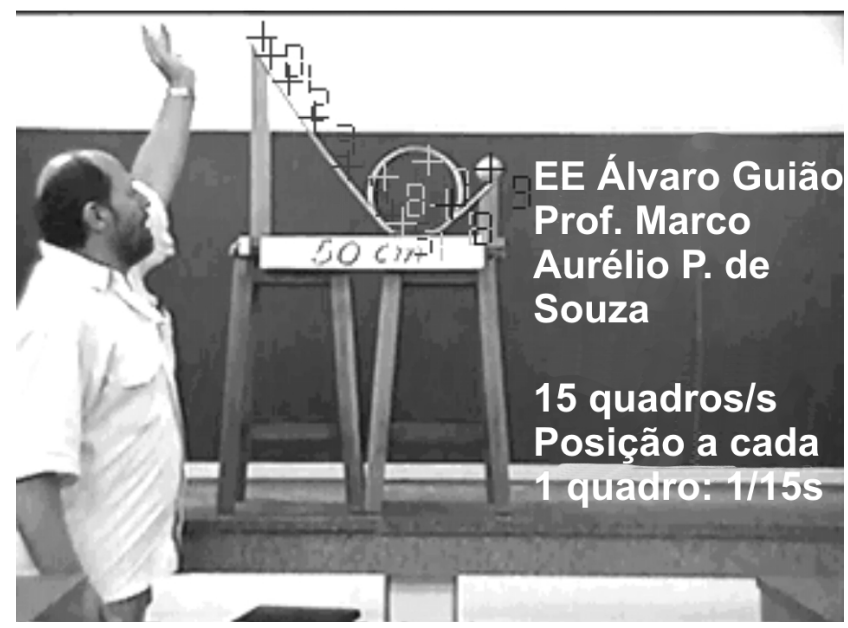

Figura 4. Looping.

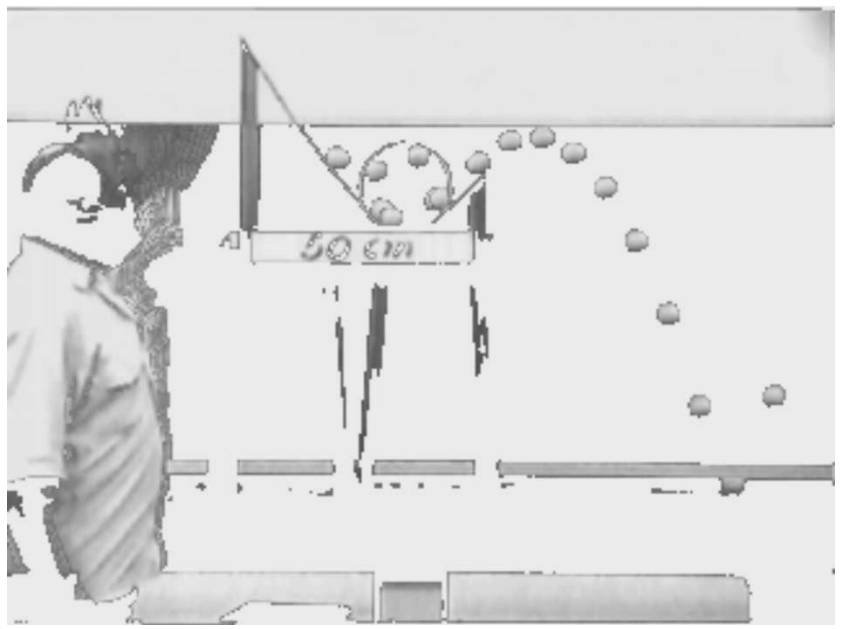

Figura 5. Looping - estrobo. 


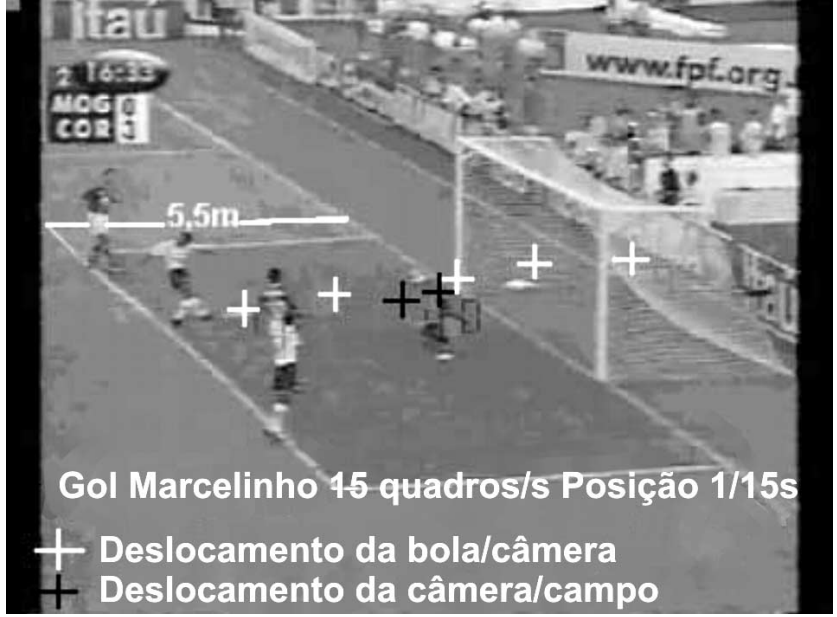

Figura 6. Movimento de uma bola de futebol.

$$
\begin{aligned}
& \text { Exemplo } \\
& \mathrm{V}_{\text {bola } / \text { campo }}=\mathrm{V}_{\text {bola } / \text { câmera }}+\mathrm{V}_{\text {câmera } / \text { campo }}= \\
& =6,95 /(4 / 15)+0,68 /(4 / 15) \\
& \mathrm{V}_{\text {bola } / \text { campo }} \sim 26,0 \mathrm{~m} / \mathrm{s}=96,0 \mathrm{~km} / \mathrm{h}
\end{aligned}
$$

\section{Avaliação do Projeto}

O projeto está em avaliação contínua elaborada a partir de Magalhães [16] e nele foram aplicados métodos de avaliação quantitativos - através de questões fechadas e qualitativos - através de questões abertas. Na análise dos dados quantitativos foi utilizada a escala Likert de 5 pontos, onde 1 - Muito Fraco, 2 - Fraco, 3 - Médio, 4 - Bom e 5 - Muito Bom [16]. As avaliações realizadas no decorrer do projeto foram as seguintes:

- Avaliação diagnóstica dos alunos das escolas públicas para levantar as concepções espontâneas dos alunos de espaço, tempo, velocidade e dos pré-requisitos de matemática necessários para o desenvolvimento do conteúdo.

- Avaliação do projeto pelos professores dos minicursos.

- Avaliação formativa dos alunos e dos professores das escolas públicas participantes, relacionada à utilização do software em sala de aula, dificuldades apresentadas, apreensão dos conceitos científicos dos alunos e outros (17).

\section{Análise dos Resultados}

a) A Fig. 7 mostra dados quantitativos obtidos durante a Avaliação Formativa do Curso utilizando o SAM para 33 alunos da E.E. Tomas Whately de Ribeirão Preto-SP [18].

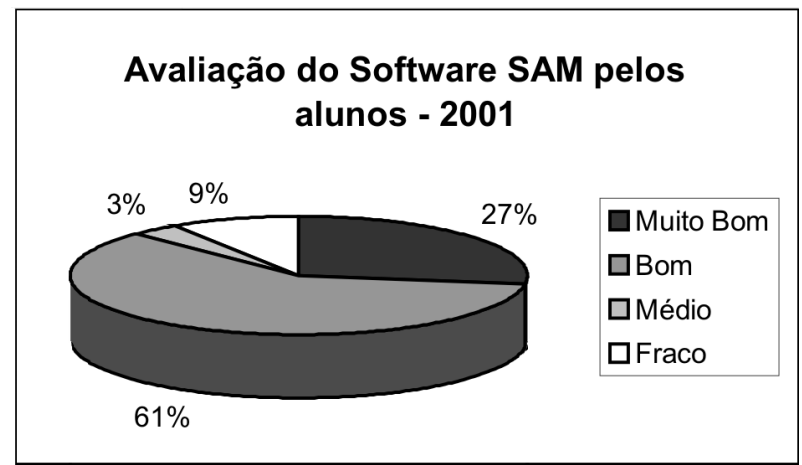

Figura 7. Avaliação do uso do software SAM pelos alunos da E.E. Tomas Whately, Ribeirão Preto-SP [18].

b) Os dados qualitativos obtidos da avaliação do software SAM pelos quatro professores das escolas públicas mostraram que, além de o além do software possibilitar o estudo de situações do cotidiano do aluno facilitando a aprendizagem, deixou-os entusiasmados com a captura de imagens e o recurso de estrobo permitido pelo SAM. A Fig. 8 mostra os resultados quantitativos obtidos da avaliação do software SAM pelos professores das escolas públicas, onde 1- Muito Fraco, 2 -Fraco, 3 - Médio, 4 - Bom e 5 - Muito Bom [19].

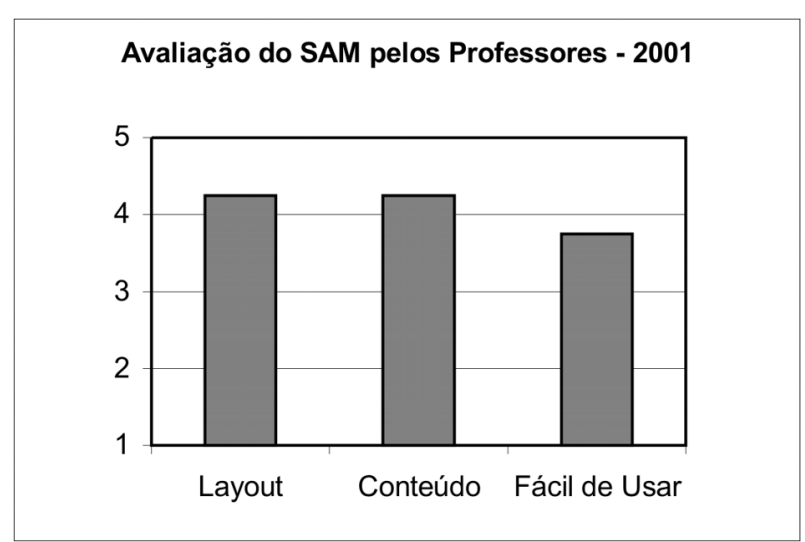

Figura 8. Avaliação do software SAM pelos quatro professores participantes do projeto, no ano de 2001 [19].

c) Os dados qualitativos obtidos na avaliação aplicada no minicurso do SAM mostraram que os professores da região de São Paulo, participantes do Programa Pró-Ciências-FAPESP, acharam que seria necessário mais tempo para ele. Com relação ao SAM, gostaram de suas ferramentas e do fato de trabalhar com imagens reais. A Fig. 9 exibe os dados quantitativos sobre o software SAM obtidos de 12 questionários respondidos durante a avaliação aplicada no minicurso do SAM, ministrado para 26 professores da região de São Paulo participantes do Programa Pró-Ciências, nas dependências da PUC/SP, onde 1 - Muito Fraco, 2 Fraco, 3 - Médio, 4 - Bom e 5 - Muito Bom [20]. 


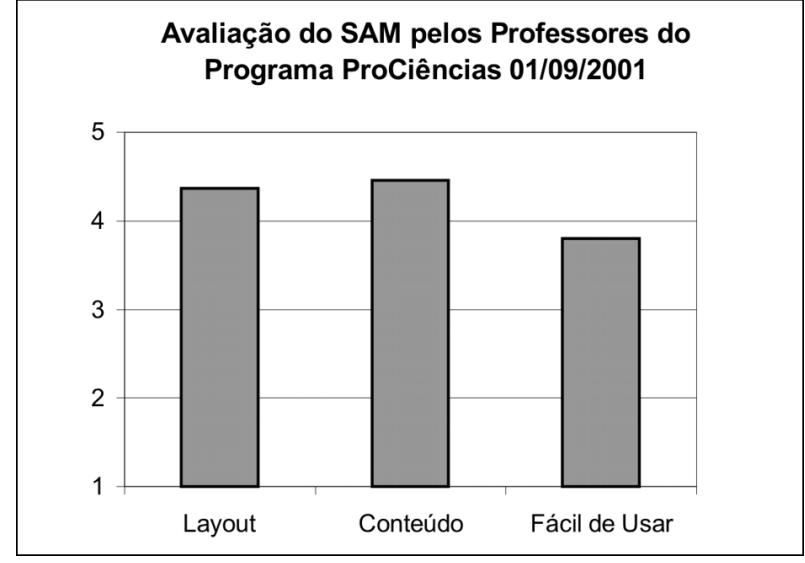

Figura 9. Avaliação do software SAM pelos professores da região de São Paulo participantes do Programa PróCiências-FAPESP [20].

d) Durante o desenvolvimento deste projeto nas escolas parceiras, pudemos averiguar dificuldades em acessar a Internet, além da existência de poucos computadores.

\section{Conclusões}

A avaliação diagnóstica realizada nas escolas públicas participantes mostrou que os alunos apresentam falta de pré - requisitos em matemática, sendo necessário que os professores de física os complementem durante as suas aulas.

$\mathrm{Na}$ avaliação quantitativa do software SAM realizada pelos professores e pelos alunos, foram obtidos dados que mostraram como sendo bom o uso do software.

O ambiente de aprendizagem com a utilização do software, considerando-se as atividades desenvolvidas pelos professores nas escolas públicas participantes, foi avaliado parcialmente. Foi observado que o aluno fica motivado, procurando interpretar o mundo real uma vez que os movimentos analisados fazem parte do seu cotidiano, facilitando a aprendizagem das concepções científicas, indicando que o software pode ser, para o aluno, uma ferramenta de aquisição do conhecimento.

\section{Agradecimentos}

Agradecemos aos professores bolsistas da Rede de Ensino Público participantes do Projeto: Marco Aurélio Pillegi de Souza, Pedro Antonio Jucosky, José Alexandre Machado e Maria Fernanda do Carmo Gurgel; à FAPESP (Fundação de Amparo à Pesquisa do Estado de São Paulo) pelo apoio e à equipe do CDCC/USP (Centro de Divulgação Científica e Cultural da USP).

\section{Referências}

[1] Hewit, J.; Brett C. \& Scardamaglia, M. Design Principles for Support of Distributed Processes. Available on the WWW at:

http://csile.oise.on.ca/abstracts/distributed/

[2] Khan, B. H., ed. Web-Based Instruction. Educational Tecnology Publications, Inc., Englewood Cliffs, New Jersey (1997).

[3] Glennan, T. K. \& Melmed A. Fostering the Use of Educational Technology: Elements of a National Strategy. RAND, Santa Monica, CA (1996).

[4] Physical Science Committee (PSSC). Física Parte II. Livros Técnicos e Científicos (1965).

[5] Forcier, R. C. The Computer as Educational Tool Productivity in Problem Resolving. Prentice Hall, inc. $2^{\text {nd }}$ ed. (1999).

[6] Villani, A. \& Pacca, J.L.A. Construtivismo, Conhecimento Científico e Habilidade Didática no Ensino de Ciências. Rev. Fac. de Educ. 23 (1-2) (1997).

[7] Simon, P. R. J. Construtive Learning: The Role of the learner. In: Duffy, T. M., Perry, D. J. (Eds). Constructivism and The Tecnology of Instruction - A Conversation. (1993).

[8] Duffy, T. M. \& Jonassen, D. H. (ed.) Constructivism and the Tecnology of Instruction . Lawrence Erlbaum Associates Publishers, Hillsdale (1992).

[9] Kosman, R. B. Learning with Media. Review of Educational Research, 61 (2) (1991).

[10] Duffy, T. M. \& Cunningham, D. J. Constructivism Implications for the Design and Delivered of Instruction. In: Jonassen, D. H., ed. Educational Communications and Tecnology. Macmillan Library Reference, New York (1996).

[11] Jonassen, D. H. Computers in the Classroom - Mindtool for Critical Thinking. Ed. Prentice Hall, Inc. New Jersey (1996).

[12] Schank, C.K. \& Edelson, D. J., A Role for All in Education: Using Technology to Reshape Education. J. of Artif. Intellig., Winter (1990).

[13] Muller, J. The great Logo Adventure - Discovering Logo on and off the computer. Doone Publications, Madison, Al, USA (1997).

[14] Papert, S. Logo: Computadores e Educação. São Paulo, Brasiliense (1988).

[15] http://educar.sc.usp.br/sam - Software para Análise de Movimentos - SAM.

[16] Magalhães, M. G. M. Estudo e Avaliação de Educação à Distância utilizando a Tecnologia $W W W$. Dissertação de Mestrado. São Carlos, Instituto de Física, Universidade de São Paulo, (1997).

[17] Schiel, D. Rede de Ensino de Fúsica à Distância - Parte II. Análise Quantitativa de Movimentos: Uma atividade para alunos do Ensino Médio. Relatório FAPESP (2001).

[18] Magalhães, M. G. M. Avaliação Formativa do Curso utilizando o SAM pelos alunos. São Carlos. Relatório Técnico CDCC-USP, 2 (2001). 
[19] Magalhães, M. G. M. Avaliação do SAM pelos professores das escolas do projeto Análise Quantitativa de Movimentos/FAPESP. São Carlos. Relatório Técnico CDCC-USP, 3 (2001).
[20] Magalhães, M. G. M. Avaliação do minicurso e do software SAM pelos professores do Programa PróCiências/FAPESP. São Carlos. Relatório Técnico CDCC-USP, 4 (2001). 